\title{
A bioeconomic analysis of the impact of decommissioning programs: Application to a limited-entry french scallop fishery
}

\author{
Guyader Olivier ${ }^{1,}{ }^{\star}$, Daures Fabienne ${ }^{1}$, Fifas Spyros ${ }^{2}$
}

\author{
${ }^{1}$ Marine Economics Service, Institut Français de Recherche pour l'Exploitation de la Mer (IFREMER), \\ BP 70, 29280 Plouzané, France \\ ${ }^{2}$ Fisheries Resources Department, Institut Français de Recherche pour l'Exploitation de la Mer \\ (IFREMER), BP 70, 29280 Plouzané, France \\ *Corresponding author : Olivier Guyader, email address : oguyader@ifremer.fr
}

\begin{abstract}
:
The objective of this paper is to assess the benefits and costs of decommissioning policies aimed at reducing fleet capacity through premiums offered by the public authority to fishermen to scrap their vessels. A case study, the limited entry scallop fishery of the Saint Brieuc Bay, France, is used to consider the problem of excess capacity and to model the bioeconomic consequences of disinvestment behavior. Special attention is paid to the assessment of fishermen's willingness to leave the fishery and to the implementation of public policy in terms of budget level and premiums offered to the fishermen. Spreadsheet simulations show that the impact of decommissioning programs is positive in terms of net surplus, even in the case of increasing technical efficiency of the vessels.
\end{abstract}

Keywords : Fishing capacity, decommissioning programs, premium, willingness to leave, bioeconomic model, cost-benefit analysis

JEL Q22

This study is part of the EU funded project "The sinificance of Economic Incentives in Fisheries Management under the CFP" (FAIR PL97-3936) 


\section{INTRODUCTION}

There is an increasing concern about excess capacity in the fisheries at an international level as well as in the European Union (FAO 1997) (Gréboval and Munro 1998; 1999) (Hatcher and Robinson 1998). The economic analysis of these problems has focused on the factor explaining overcapitalisation and the policy options - market based or administrative systems - to control and reduce fishing capacity of the fleets (Newton 1998) (OECD 1997) ${ }^{1}$. Within management alternatives, buyback or decommissioning programs of vessels or licences is one of the tool used by countries to adjust their fleets in order to reach different objectives (Holland and al. 1999) (Holland 1999) (Metzner and Rawlinson 1998). They have been widely used to restore profitability to the fishery, to reach stock conservation objectives but they also lead to distributional implications in terms of transfer payments.

At European level, Adverse effects on fishing stocks (Anon 1990) (Anon 1996) has led to strengthen the role and to harden the constraints of Multi Annual Guidance Programs (MAGPs) within the Common Fishery Policy. Each member state has been required to adjust the national fleet through the MAGP since 1983. Their objectives expressed in term of kiloWatt or gross registered tonnage of the fleets are linked to some general objectives expressed in terms of fishing mortality reduction. Faced by the increased tightening up of the MAGP objectives, the member states have implemented different types of public policies and decommissioning programs to fulfil fleet capacity reduction targets (Frost and al. 1995) (Nautilus 1997) (Anon 1997). In France, a sector-related policy based on entry barriers and individual permits has been used to control the fleet capacity. From 1991 to nowadays, vessel decommissioning programs linked to a premium offered by the government to the vessel owners has been adopted to reduce the fleet size (Guyader and Daurès 2000).

Despite policy interest in decommissioning programs, there is few quantitative analysis of the implication of these programs from an economic point of view (Anderson 1998) (Chuang 1998; 1999). Bio-economic analysis of fleet 
adjustments do not include the cost of such programs and then overestimate their social benefits. Even if there is an administrative cost to organise such schemes, the main cost consists of the premiums offered by the management authorities to the fishermen to scrap their vessel. On another side, most of the approaches fail to integrate the fishermen behaviour in the analysis and the impact of different economic incentives (current returns in the fishery, opportunity costs, premium level, ...) on their willingness to dis-invest. Ikara and Odink (1999) used empirical data to examine fishers resistance to exit and only few recent papers deal with the decision to leave or to stay in the fishery sector (Wenniger and Just, 1997) (Guyader, 1998ab). Moreover, the feedback effects of capacity adjustment on fishermen decision to withdraw from the industry are most of the time not considered and this can lead to a mis-specification of the public policy.

The main objective of the paper is to provide a bio-economic simulation model in order to assess the impact of capacity reduction programs on fishery performance over a transition period. The limited entry scallop fishery in the Saint-Brieuc Bay (France) is used to apply the model and the first part of the paper describes the fishery and the management options used to control the fleet fishing capacity.

In this paper, we assume that ship owners - and also skippers in the context of small-scale production - are able to value their net present benefits (or losses) to stay in the fishery, the opportunity cost, or their current benefit if they leave the fishery. The calculation gives us the evolution of the minimum willingness to accept (WA) to leave the fishery, compared to the premium offered by the decommissioning schemes elaborated by the public authority. This approach is further combined with a bio-economic simulation model

The first part of the paper The second section presents the bio-economic model used to assess the potential benefits of fleet reduction. On a third stage, a micro-economic approach is developed to model individual decisions to stay or to leave the fishery in the context of decommissioning programs. As a function of premium level, public budget constraints, simulations are carried out in order to propose a cost-benefit and a cost- 
effectiveness analysis of different capacity adjustment policies. The problem of technical progress and increasing efficiency of fishing vessels is considered as well as the windfall gains effects due to the lack of information in the implementation of public policy.

\subsection{The Scallop fishery in the Saint-Brieuc Bay.}

The Saint-Brieuc scallop fishery is located within the Occidental part of the English Channel (ICES area VIIE) and is not shared with other European countries. This is one of the two main scallop production areas in France with the Seine bay stock. Annual official landings have reached around 3800 tons since the beginning of the 90's when the national production fluctuated around 10000 tons per year. The area is exploited by vessels using dredge gear which come from the maritime districts of the North of Brittany. The fleet is composed of small units (average of 10.3 meters long and $127 \mathrm{~kW}$ for their engine power) which are multipurpose vessels carrying out trawl, gillnets, pots, etc., outside the scallop season from October to April and outside the in-season fishing time ${ }^{2}$. The scallop turnover has oscillated between 30 à 100 MF (base 1995) over the last twenty years and the fishery is a structuring activity for the coastal fleets of the area. The changes in production over the period are mainly due to modified stocks productivity and change in the fishing mortality.

Figure 1. Evolution of the scallop landings and turnover of the Bay

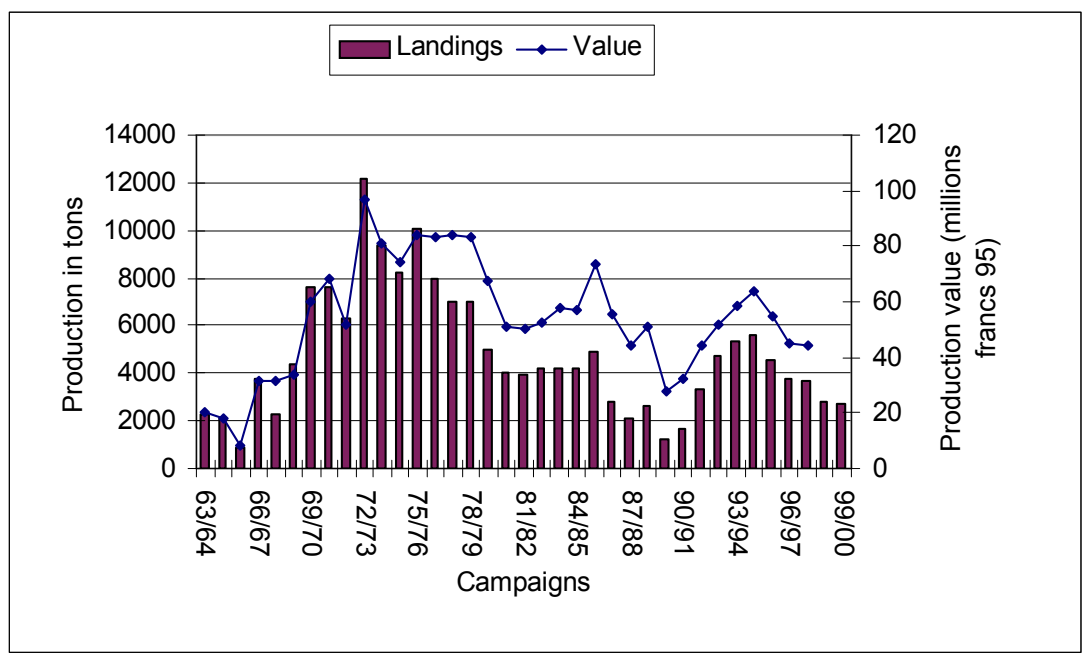

Source : IFREMER, OFIMER 
Scallop recruits are considered as highly variable (factor 1 to 15 ) and this is a disadvantage for the long trend management of the fishery, based on an average situation. Relation between genitors and recruits is mainly disguised by environmental factors (Fifas et al. 1990). Notwithstanding the good reproductions of the beginning of the 90', the potential fecundity index used as a proxy of the adult biomass has plummeted in the last fifteen years. Its level is now situated at about 10000 tons versus 30000 tons in the 70 's but the stock is not considered as to be threatened by extinction. As a consequence, landings fell from around 10000 tons at the middle of the 70 's to 1500 tons at the end of the 80 's. After the increase of the beginning of the 90 's and despite new management measures, the scallop fishery faces a new fall in official landings from 4200 tons for the 1995/96 fishing season to around 2800 tons for the 1998 and 1999 seasons.

\subsection{Management of the fishing capacity by fleet adjustment}

The development of the scallop fishery is mainly explained by the switch of the coastal fleets from the clam fishery which collapsed in the 60 's. In order to avoid the same event and to control fishing mortality in an indirect way, the management authorities decided in 1963 to limit entry in the fishery. Input regulations such as hours at sea, maximum engine power, vessel length and mesh size limits were also implemented. The licence system with a numerus clausus was put into force in 1973 with allocation based on historical rights. Finally, 466 licences were issued to the vessels from the main maritime districts for the 75-76 fishing season and this number declined to 447 in 1980, to 371 in 1985. The scallop fleet decrease went on to reach respectively 282, 264 units in 1990 and 253 in 1997. Different factors may explain the 45 percent reduction over the period. First of all, the decline of the scallop stock during the 80 's and the relative remuneration fall in the fishery give fishers incentives to leave it to other best alternatives. This implies that the fishing capital has not left the fishery sector. Second, natural retirement of fishers occurred and the management authority decided not to allocate all the free licences to the candidate for entry. The exit flows leads to distributive effects because most of the vessels excluded were from maritime districts 
outside the Saint-Brieuc Bay; 85 percent of the vessels are now from Bay versus 65 percent in 1980. Finally, scallop vessels have been recently scrapped by different French decommissioning programs applied into the context of the Multi-annual Guidance Programs of the Common Fishery Policy ${ }^{3}$. Decommissioning programs were not dedicated specifically to the scallop fishery because there was not a discriminative policy within the French fishery sector (Guyader and Daurès 2000). Moreover, the scallop fishery regulators did not adjust the fleet size in proportion to the vessels scrapped.

Figure 2. Evolution of vessel number in the scallop fishery

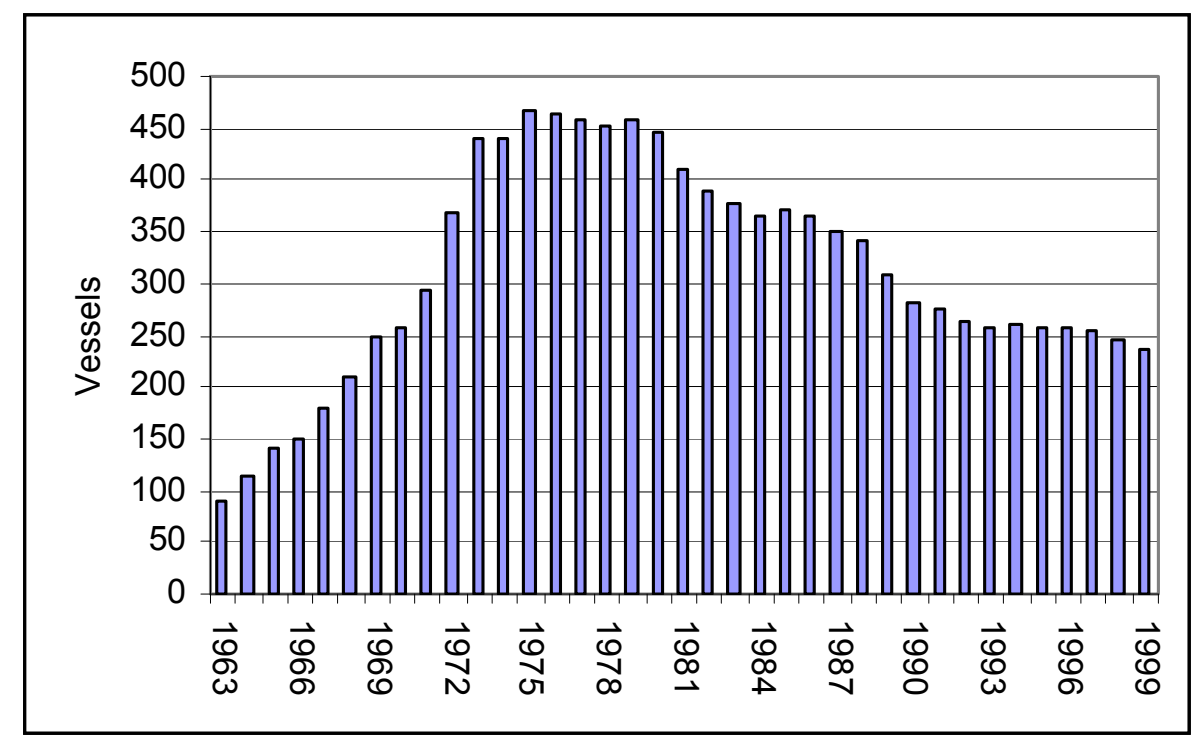

Source : IFREMER 
Figure 3. Fleet characteristics indexes

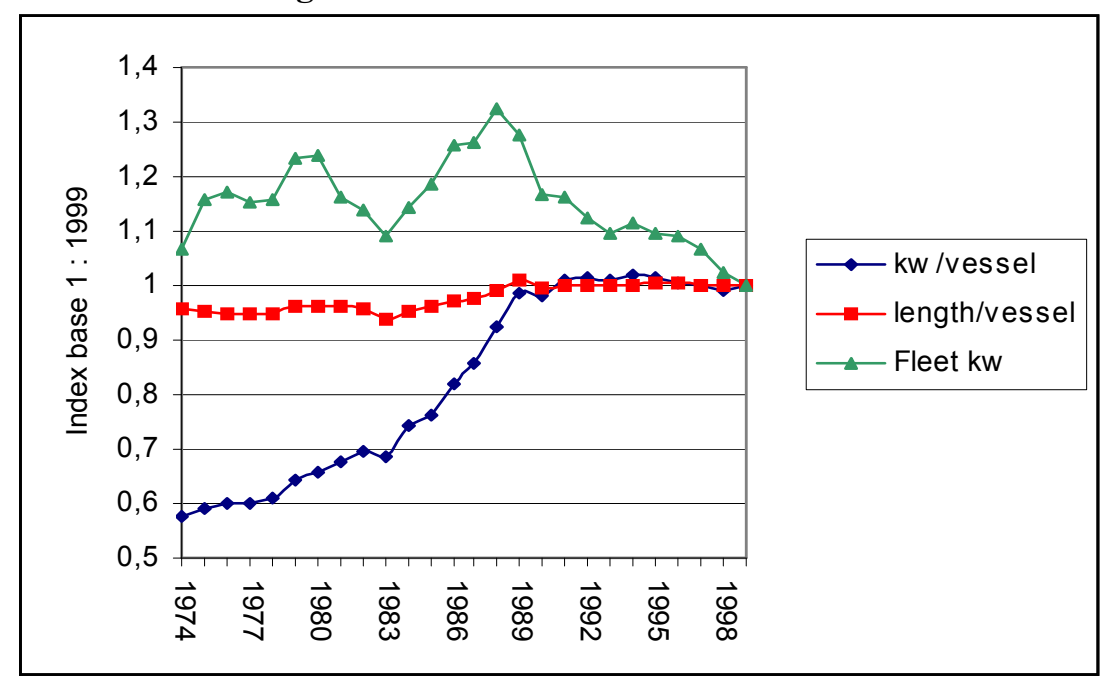

Source : IFREMER

The management of input regulation has not been really effective in controlling the fishing power of the fleet.

Even though maximum limits for vessel characteristics had been implemented ${ }^{4}$, there were economic incentives for vessel owners within the fleet to increase engine power by buying other vessels or upgrading the older ones before the implementation of fishing permits in 1989 which aimed at controlling it ${ }^{5}$. Since this period, capital stuffing has been still increased through investment in electronic fittings and improving skills (Guyader and Fifas 1999). The increasing mean engine power does not explain the global improvement of the fleet's fishing capacity. Clearly, yields are better than those observed in the mid 1980s for a similar stock level. That is why management authorities decided to reduce days and hours at seas (from 120 to 43 hours between 1973 and 1997) in order to adjust the catches level to the state of the resources and to balance out the production over the years. By evidence, the allocation of individual quotas in this single species fishery could have prevented the dynamics of overcapitalisation of the fleet by giving a right to the catch for each fishing unit. However, this management option has been always rejected until now. It is seen as unenforceable by the management authority because of the risk of cheating behaviour in this coastal fishery.

\section{The bio-economic model without fishermen behaviour}


This section presents the framework of the bio-economic model defining the link between the situation of the fleet and sub-fleets in terms of vessel number and the dynamics of the scallop stock as well as the feed back effects of the stock situation on the economic results of the fleet. The scallop biological model is age structured in order to take into account for growth and gear selectivity (Fifas 1993) and the vessel production or harvesting function is defined as :

$y_{v j}=q_{v j}\left(N_{j}\right) \cdot E_{v} \cdot N_{j}$

The model is annual and the subcript for time are considered in the presentation. For each vessel $(v)$, the individual catches per age group $(j)$ is yvj where $\left(E_{i}\right)$ (pas besoin de i mais d'un vs) is the annual legal time spent in the fishery, $\left(N_{j}\right)$ the abundance of the age-group $j$ and $q_{v j}$ the catchability coefficient for each age-group of scallops (Fifas 1991 ; Fifas 1993) Basically, ages from 3 to 6 are subject to harvest:

$q_{v j}\left(N_{j}\right)=\exp \left[\frac{N_{j}^{k W v}}{\alpha+\beta \cdot N_{j}^{k W v}}\right]$

The catchability coefficient depends on the level of the biomass and the vessel engine power (explication spyros)

With: $\beta<0, \alpha>0$ (for cohorts 2 and 3), $\alpha=0$ (for cohorts 4 and more).

\section{All the other relations are presented in annex (selectivity...)}

Total individual vessel catch of scallops per year is then :

$y_{v s}=\sum_{j=1}^{N} y_{v j}$

On the basis of the vessel production function, economic indicators can be defined. We suppose in this paper that the landing price of scallop and that price of intermediate consumption are fixed. 
The revenue to be shared (rts) between the vessel owner and the crew :

$r t s_{v}=p_{s} \cdot y_{v s} \cdot(1-\beta)-c_{v s} \cdot E_{v s}+\sum_{o=1}^{N} p_{o} \cdot y_{v o} \cdot(1-\beta)-\sum_{o=1}^{N} c_{v o} \cdot E_{v o}$

with $\left(y_{v s}\right)$ and $\left(y_{v o}\right)$ the level of catches of scallop and other species, $(\beta)$ the unit cost of landings, $\left(E_{v s}\right)$ and $\left(E_{v o}\right)$ the days at sea spent in the scallop and in the other fisheries, $\left(c_{v}\right)$ the unit cost of a day at sea. We assume that the activity of the vessel is constant in terms of targeted species and days spent into the different fisheries. The price of the scallop and other species is fixed for the simulation ${ }^{6}$.

According to the share system of the revenue, the net capital stream $\left(n c s_{v}\right)$ earned by the vessel owner each year is :

$n c s_{v}=\alpha_{v} \cdot r t s_{v}-o c_{v}$

with : $\left(o c_{v}\right)$ the other costs of the vessel, like repairs, maintenance, loan interests, cost of the investments.

Most of the time, vessel owners are also skippers of the boat, which means that they are paid as part of the working force and for their skills. As a consequence, the annual net labour stream for the skipper $\left(n l_{v}\right)$ is given by :

$n l s_{v}=\left[\left(1-\alpha_{v}\right) \cdot r t s_{v}-s i c \cdot C_{v}\right] / C_{v}$

with : $\left(\alpha_{v}\right)$ and $\left(1-\alpha_{v}\right)$ the share of the revenue allocated to respectively the owner and the crew . $\left(C_{v}\right)$ is the crew 
size and (sic) the social insurance cost per crewmember.

The individual vessel producer surplus is given by :

$p s_{v}=n c s_{v}-o c c_{v}+n l s_{v} \cdot C_{v}-o c l_{v} \cdot C_{v}$

where $\left(o c c_{v}\right)$ and $\left(o c l_{v}\right)$ are respectively the opportunity cost of capital and labour.

\section{Segmentation of the fleet and economic indicators}

Bio-economic simulations are established according to a relevant fleet segmentation. For the analysis, the scallop fleet is divided into four categories expressed in terms of engine power $(\mathrm{kW})$ with different level of turnover and costs for each sub-segment. Around 253 vessels were active over the 1993-1998 period. The economic parameters comes from the surveys on the Channel fleet (Boncoeur and Le Gallic 1999) but also from other database.

Table 1. Figures concerning the scallop fishery - average data over the 1993-1998 period

\begin{tabular}{ccccc}
\hline Fleet segments & {$[0-60 \mathrm{~kW}]$} & {$[60-120 \mathrm{~kW}]$} & {$[120-185 \mathrm{~kW}]$} & {$[>185 \mathrm{~kW}]$} \\
\hline Number of vessels / category & 26 & 101 & 96 & 30 \\
$\mathrm{~kW} /$ vessel & 44 & 92 & 151 & 242 \\
Crew / vessel & 1.5 & 1.9 & 2.5 & 3.5 \\
Scallop landings / vessel (tons/year) ${ }^{*}$ & 7.1 & 20.4 & 22.5 & 23.1 \\
Scallop turnover / vessel (KF**)* & 95.1 & 275.6 & 297.4 & 306.9 \\
Total turnover minus variable costs / vessel** & 213 & 514 & 743 & 1330 \\
\hline
\end{tabular}

* Simulation results $* * \mathrm{KF}=$ Thousands francs

It is then possible to simulate the consequence of different fleet size on the bio-economic situation of the fishery. As illustrated on the last figure, producer surplus but also stock situation will be improved by fleet reduction considering other regulations as a constant. A 45 percent increased producer surplus will be obtained with only 30 percent of the current fleet level and stock fecundity improvement will increase the probability to reach better 
recruits in the future.

Figure 4. Long term effects of different fleet sizes level

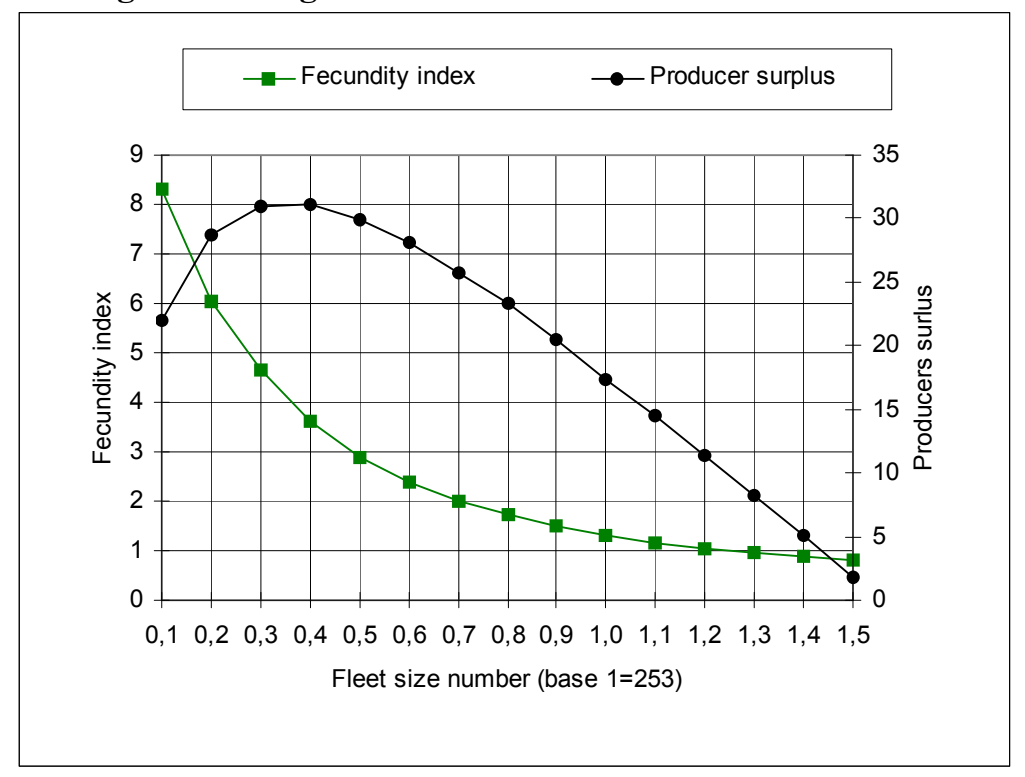

Note : sustainable level with current regulation on days at sea

As a consequence, the reduction of the fleet can lead to positive effects from an economic efficiency perspective. The problem is that this valuation does not take into account the cost of the public policy and then overestimate the net benefits of capacity reduction. The next section considers this issue by integrating a micro-economic model of exit to the previous bio-economic model.

\section{Willingness to stay or to leave the fishery.}

In the model, the decision to stay or leave the fishery depends on the fisherman's estimation of his expected benefits regarding a "staying-leaving ratio". The net present value of fishing activity (npv) discounts the sum of annual economic net flows during the actualisation period (see equality 1$)$. The actualisation period $\left(T_{i}-t\right)$ is the delay between the period of retirement of each fisherman (i) and the current period $(t) .(r)$ is the individual psychological discounting rate to consider fishermen's preference for time. Yet, we use the capital cost funding rate or the opportunity cost of capital in order to take care of the present value of different alternatives ${ }^{7}$. Due to the 
uncertainty inherent to fishing activities, it may also include a risk premium.

The net present value of staying in the fishing sector is the sum of different elements; the present value of net capital flow extracted from the fishery, the selling price of the boat $(P K)$ at the end of the actualisation period $(T)$. Even if the price of the boat on the second hand market depends on regulations and public subsidies granted to the fishing sector, we consider that each ship value is the deflated purchase value of the fishing unit including the value of investments (engine, electronics and other equipment), and deducting the economic depreciation of the capital $^{8}$. The boat value is then exogenous to the model and does not depend on fishing incomes that could be capitalised in it. Finally, the net present value of fishing activities and that of staying into the fishery includes the present value of net labour income flows for the skipper, if he is also the boat owner. Note that the basis for net capital and labour flow calculation can be changed within the model. The last period, or the average net incomes over a given past period, may be used to reflect the income expectancies in the future.

Consequently, the expected net present value of staying is:

$n p v f_{v t}=\sum_{t=1}^{T_{i}} p s_{v t}(.) /(1+r)^{t}+P K_{v T_{i}} /(1+r)^{T_{i}}$

On the other hand, the present value of leaving the fishery can be expressed as follows :

$n p v e_{v t}=s_{b t} \cdot g r t_{v}+\sum_{i=1}^{T_{i}} w_{v t} /(1+r)^{t}$

where: $\left(w_{v t}\right)$ is the opportunity cost of labour that each fisherman $(i)$ may expect to earn elsewhere in the economy. The last right term of the equality represents the net present value of labour, out of the fishing 
activity. $\left(s_{b}\right)$ is the unit premium per ( $\left.g r t\right)$ Gross Registered Tonnage allotted by the administration to fishermen to decommission their boat. In such a situation, each vessel owner has an alternative to leave the fishery, either by selling his boat on the second hand market at the current period, or by withdrawing his boat in counterpart of the premium offered.

The decision rule to stay or to leave the fishery at any time of the simulation depends on the form of the inequality:

$n p v f_{v t} \geq{ }_{n p v e_{v t} \quad \forall t=1, \ldots T}$

The right side of the inequality can be viewed as the opportunity cost of staying in the fishery. As shown hereafter, the fisherman leaves (or stays in) the fishery when the net present value of fishing is less (or more) than the net present value of leaving. The unit premium per grt, for which the two options equal, is deducted from inequality (13).

$s_{v t}^{*}=\left[\sum_{t=1}^{T_{i}} p s_{v t}(.) /(1+r)^{t}+P K_{v T_{i}} /(1+r)^{T_{i}}+\sum_{i=1}^{T_{i}} w_{v t} /(1+r)^{t}\right] / g t_{i}$

This quantity expresses the minimum willingness to accept (WA) per grt necessary to incite the vessel owners to leave the fishery, based upon the agent's expectations. It should include working satisfaction bonus or loss (as does Anderson, 1980 and underlined by Frost and al. 1995) that reflects the fisherman's interest in the job. The valuation of this component is not possible in this study, owing to a lack of information on every agent of the case study. 


\section{Application to the decommissioning plan}

As is a common practice for the French government's decommissioning programmes, the public authority decides to fix the premium per grt. This unit premium $(s)$ is the same for all the of vessels,. The annual budget ( $\left.B_{t}\right)$ for the administration is limited and is available for a certain period $(D)$, the duration of the decommissioning plan. The number of vessels $\left(V_{t}\right)$ elected to the annual programme is defined so that the firms with the lowest WA first exit the fishery. The rule of exit is :

$s_{t}^{*} \equiv \min _{v}\left(s_{v t}^{*}\right)$

if $s_{t}^{*} \leq s_{t}$ then

$V_{t} \equiv \max _{v}\left(V\left(s_{t}^{*}\right)\right)$ subject to $s_{t} \cdot g r t_{v} \cdot V\left(s_{t}^{*}\right) \leq B_{t}$

If the minimum WA is lower than the premium offered by the public authority, the number of eligible fishermen is calculated in order to exhaust the budget and (or) to satisfy the applicants. This being said, fishermen opportunities must be reconsidered at each iteration in the spreadsheet in order to take into account the evolution of the bioeconomic environment. The conceptual model is given in figure 5. 
Figure 5. The main simulation model components.

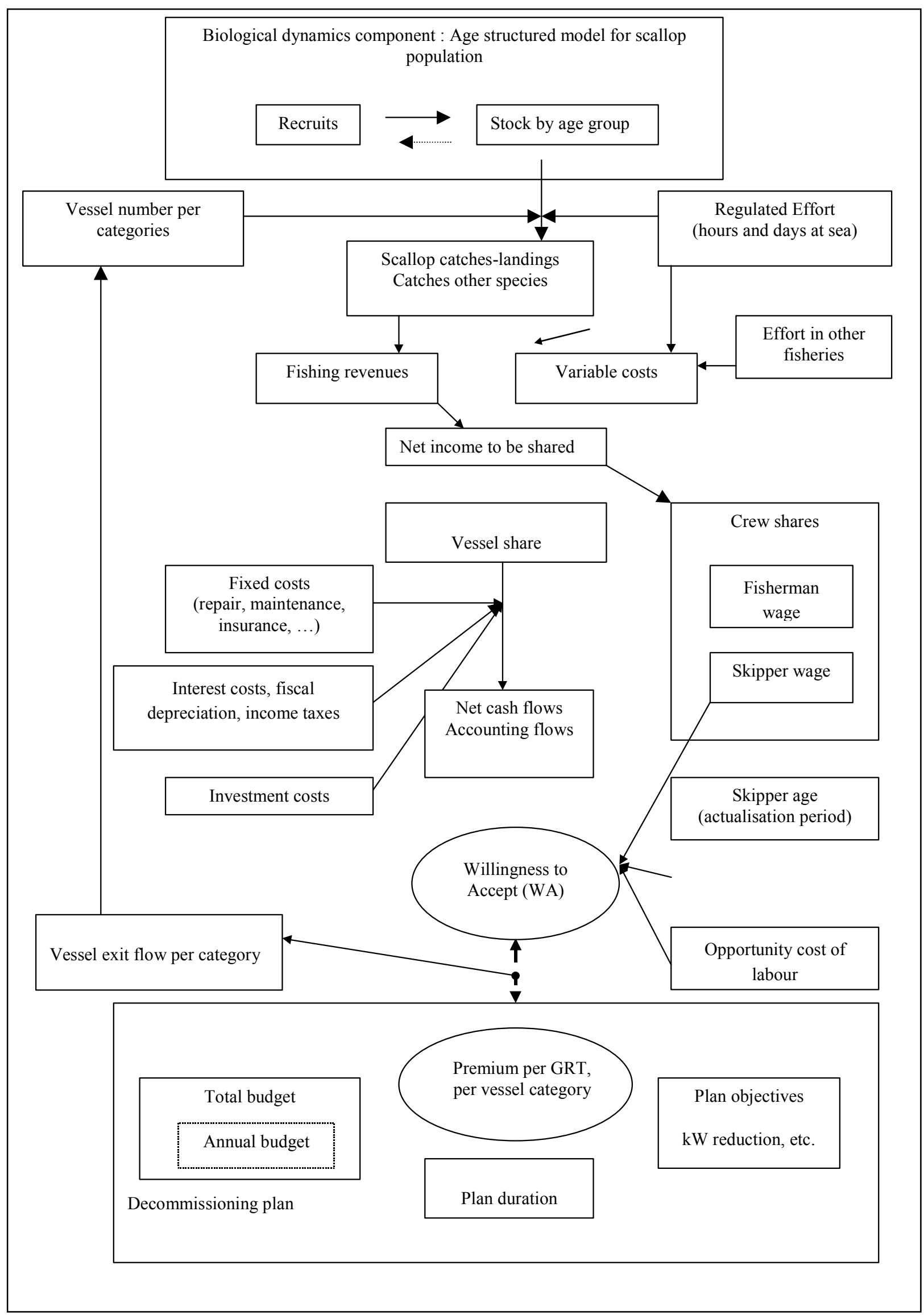




\section{Cost-benefit and cost-effectiveness analysis of decommissioning plans.}

The simulation output is carried out between the years 1998 and 2010. It reveals the evolution of different indicators such as the biomass level, that of the individual and fleet production, the fleet's turnover, but we focus in this paper on the evolution of producer surplus and decommissioning cost.

\section{Simulation of decommissioning plans.}

Initially, we compared the status quo results named as scenario \#0 with a specific decommissioning plan output (scenario \#3). The latter scenario provides administration with a 30 million franc budget that must be used in the first two years (1998 and 1999); the budget is shared out in two equal parts between the two years. The premium granted by the administration to leave the fishery is allocated according to an egalitarian basis, and is equal to 50,000 francs per grt (Basis 100).

The above tables indicate the willingness to accept (WA) for each boat category compared with the premium and the consequent evolution of the fleet's structure during the first three years. Only the first class $[0-60 \mathrm{~kW}]$ has a WA per grt, for which the value is lower than the premium granted in 1998. This is the reason why all the boats in this segment (26 units) leave the fishery. Note that such result can be obtained by simplifying assumption about the economic environment of the firms: in practice, as boats in this segment are progressively leaving, the market conditions under which the remaining ship owners operate are changing, and may even change their expectations and decisions; yet, taking such a change into consideration would be another, and much more complicated exercise. So, regarding our assumption, the annual budget available is sufficient to cover the cost of boat exits, which is estimated to be 6.02 Million francs. Then, the balance is reported to the second year of the plan, and 23.98 Million Francs are now available to be spent to withdraw 60 units of class 2. In 1999, WA declined due to 
lower revenues (lower stock level) and higher expenses resulting from the replacement of different parts of the engine. The premium is then sufficient to incite all fishermen to leave the sector (see table 3). Yet, the spreadsheet only excludes those who have the lower WA. They are probably the more interested in leaving the fishery. For them, the windfall gain per grt, that is to say the difference between premium and WA is higher.

Table 2. Evolution of the fleet structure on scenario \#3

\begin{tabular}{lllll}
\hline Boat class/Years & 1998 & 1999 & 2000 & $\begin{array}{l}\text { Variation rate } \\
1998 / 2000\end{array}$ \\
\hline $0-60 \mathrm{~kW}$ & 26 & 0 & 0 & $-100.0 \%$ \\
$60-120 \mathrm{~kW}$ & 101 & 101 & 41 & $59.0 \%$ \\
$120-185 \mathrm{~kW}$ & 96 & 96 & 96 & $0.0 \%$ \\
$>185 \mathrm{~kW}$ & 30 & 30 & 30 & $0.0 \%$ \\
Number of boats & 253 & 227 & 167 & $-34.0 \%$ \\
Total GRT & 3089 & 2969 & 2489 & $-20.6 \%$ \\
Total kW & 32084 & 30989 & 25465 & $-20.6 \%$ \\
\hline
\end{tabular}

Note: Basis for income actualisation: current year. Discounting period $=15$ years

Table 3. Minimum willingness to accept to leave the fishery

\begin{tabular}{cccc}
\hline Indicators/Years & 1998 & 1999 & 2000 \\
\hline Average WA/GRT 0_60 kW & 33.56 & - & - \\
Average WA/GRT 60_120 kW & 64.36 & 34.35 & 58.68 \\
Average WA/GRT 120_185 kW & 55.10 & 36.47 & 56.19 \\
Average WA/GRT >185 kW & 56.82 & 46.51 & 57.48 \\
Total WA for fleet & 176.5 & 114.9 & 141.7 \\
Average WA/boat & 0.698 & 0.506 & 0.848 \\
Average WA/GRT & 57.17 & 38.72 & 56.95 \\
\hline
\end{tabular}

Figures in thousands francs, WA as Willingness to Accept

Regarding the adjustment of the whole fleet, $34 \%$ of the scallop fleet and $20.6 \%$ of the total fishing capacity expressed in the form of total engine power in $\mathrm{kW}$, are decommissioned by this plan. Now, if the reduction in fishing power must reach $30 \%$, this policy can be considered as a failure, for it did not achieved its objectives. The amount spent in decommissioning schemes is 30 million Francs, whereas the model estimates at 20.53 million Francs the sum of the total WA. The difference is the total windfall gain transferred from taxpayers to fishermen and windfall gains lead to huge distribution effects. 
From an economic point of view, the impact of the status quo or decommissioning scheme can be assessed at the level of the firm and also considering the whole fleet. At the micro-level, it appears that the mean WA per kW necessary to leave the fishery increases in both cases. Now, the implementation of scenario \#3 results in higher values than status quo. It exceeds nearly 10,000 francs for an 80,000 francs value. We use macro-analysis in this study, and the indicator of producer surplus removed the from scallop activity is retained to assess the economic efficiency of the policy. Actually, boat withdrawal yields more annual economic rent than status quo, excepted for the first two years, just because the decommissioning scheme has not yet produced its effects. In 2001, the fishery will produce about an additional million franc rent and the gap will continue to increase to reach nearly some 5 million francs by 2010 (see figure 6 and 7)

Figure 6. Total scallop landings during the transition period (scenario \#0 and \#3)

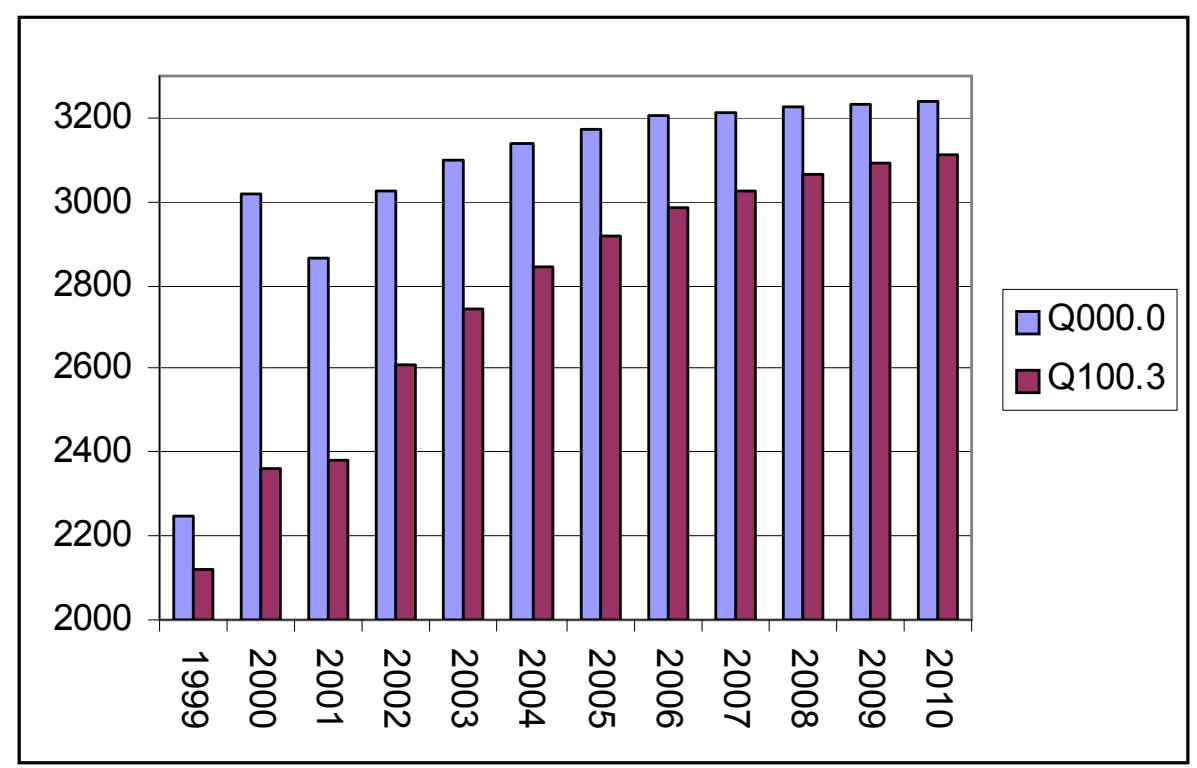


Figure 7. Total producer surplus trajectory under the scenarios $\# 1$ and $\# 3$

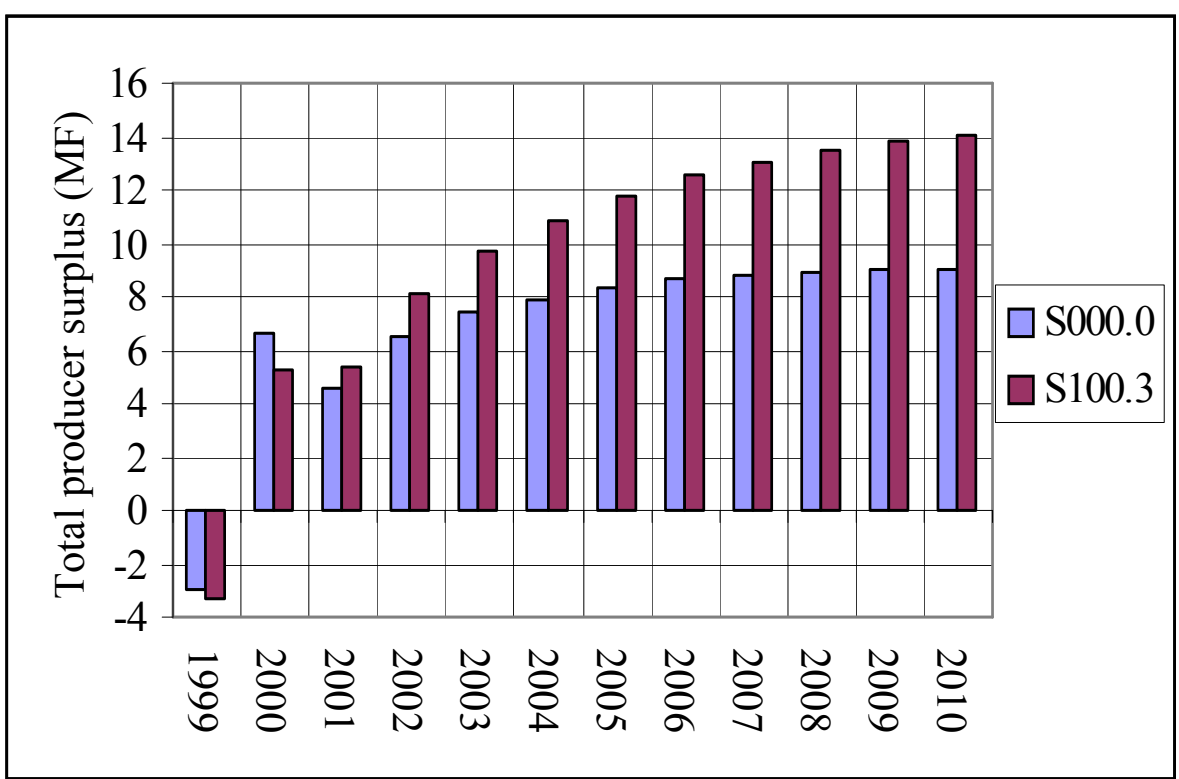

The cumulative amount of these differences represents 31.8 Million Francs, but annual flows can be discounted to take into account the preference of the public authority for time. Discount rates vary from 0 to 10 percent. For any discount rate value, the net present values (NPV) of producer surplus flows in scenario \#3 exceed NPV of the producer surplus resulting from the application of scenario \#0 (see table 4). Consequently, the implementation of decommissioning programmes can be considered as the best policy if the public authority considers this indicator as a good decision-making criteria. Moreover, the cost-benefit analysis, which relates public policy cost to surplus yields, shows that the balance is always positive, from 23 to 6 million Francs over the reference period. The difference is only cancelled for a $20 \%$ discount rate in this simulation. Even if the consequences of an improved stock situation on the evolution of recruitment have not been simulated in this paper, the basic model shows that the probability of better recruits is higher in scenario \#3, since the index of fecundity measuring the capacity of adults to give birth to recruits is also higher. As a consequence, the benefits of scenario \#3 based on a constant recruitment are probably underestimated. 
Table 4. Producer surplus and net surplus (producer surplus minus public cost) under different scenarios.

\begin{tabular}{cccccc}
\hline Discount rate & $\begin{array}{c}\text { Producer } \\
\text { surplus* } \\
\text { Scenario 0 }\end{array}$ & $\begin{array}{c}\text { Producer } \\
\text { surplus* } \\
\text { Scenario 3 }\end{array}$ & $\begin{array}{c}\text { Balance* } \\
\text { S3-S0 }\end{array}$ & $\begin{array}{c}\text { Public cost* } \\
\text { Scenario 3 }\end{array}$ & $\begin{array}{c}\text { Net Surplus* } \\
\text { Balance including } \\
\text { policy cost }\end{array}$ \\
\hline $0 \%$ & 82.9 & 114.8 & 31.9 & 9.0 & 22.9 \\
$5 \%$ & 57.5 & 77.3 & 19.8 & 8.2 & 11.6 \\
$8 \%$ & 46.9 & 62.7 & 15.8 & 7.8 & 7.9 \\
$10 \%$ & 41.3 & 54.9 & 13.6 & 7.6 & 6.0 \\
\hline
\end{tabular}

* Figures in Million Francs. Note: As scallops revenues account for 30\% of the boat turnover, we assume that $30 \%$ of the total public cost plan is dedicated to this fishery. In France, the public assessment of public scheme actually use discount rates (opportunity cost) values between $2 \%$ and $8 \%$.

Several conclusions can be drawn from this specific simulation. Though the decommissioning plan does not achieve its objective expressed in $\mathrm{kW}$, its effects are quite positive regarding its global efficiency. Producer surplus increases with the decommissioning programme, and the net surplus is also positive for a reasonable value of discount rate. Besides, technical improvements incorporated by fishermen to their boats may lead to counterproductive effects to the decommissioning programme, as well as for the status quo situation.

\section{Effects of the technical improvement.}

Regarding the increase in the technical efficiency of the boats that results from the introduction of technical improvements, the next figure reveals the dynamics of the scallop stock for different scenarios of technical progress, from 0 to $6 \%$ per year all through the simulation period, and for a 30 million francs decommissioning programme. Up to a $4 \%$ rate, the decommissioning programme leads to positive effects in terms of stock level at the end of the transition period. A higher rate conducts progressively to a degradation of the fish stock due to consecutive increasing fishing mortality. As a result, the economic situation of the reduced fleet will be affected even if a decommissioning programme is set up. However, it is more appropriate to compare the relative results of different policies rather than analyse results in absolute terms. As we can notice in the next table, the buyback policy results in better economic outcomes compared to a status quo policy for a given level of technical improvement. 
Figure 8. Evolution of the stock level as a function of technical progress rate for a $\mathbf{3 0}$ million francs decommissioning programme

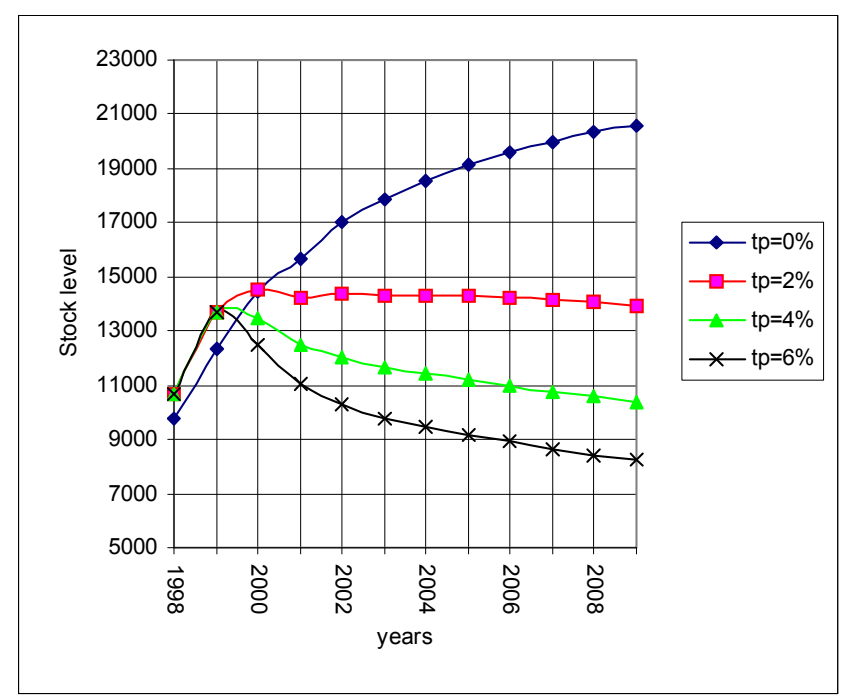

Table 5. Discounted net surplus for a 6 percent technical progress level

\begin{tabular}{ccc}
\hline & Net & Surplus (MF) \\
\hline Public discount rate & Status quo & Buyback \\
\hline $5 \%$ & 132.0 & 162.9 \\
$8 \%$ & 114.9 & 137.2 \\
$10 \%$ & 105.4 & 123.2 \\
\hline
\end{tabular}

The macro-results in terms of net surplus will lead to prefer the decommissioning solution. The problem is that increasing rent in the fishery resulting from decommissioning, will probably give rise to more and more competing behaviours between fishermen (Townsend, 1985), a phenomenon that may dissipate the created rent (e.g. technical progress will increase). In fact, the type of public policy does not reduce the incentives to increase capacity and can be seen as a tool to improve temporarily the situation of fishery. 


\section{Concluding remarks.}

Most of the bio-economic approaches do not include the cost of decommissioning programs and then overestimate the social benefits of fleet rationalization. The bio-economic tool developed leads to assessment of the potential benefits and the costs of such programs through fleet reduction. Considering the example of the overcapitalized scallop fishery, the implementation of decommissioning programs with administrative premium fixation increases the fishery net surplus compared to the status quo policy. The tool developed allows to simulate the consequences of public budget rationing which are common in most of the fisheries policies. The evolution of the net surplus through time in order to assess the consequence of the policy over a transition period. The assessment of windfall gains is also considered. In this case, the core of the problem consists in matching the premium level with the individual minimum willingness to accept to leave the fishery, in order to spare public budget or to better allocate these funds. In practice, the fishery regulator must adjust the premium level on a trial and error basis in order to minimise windfall gains. Unfortunately, this behaviour may lead to opposite effects if it does not give fishermen the right incentives. It may postpone the exits of the vessels, delays the achievement of MAGP objectives and finally increases the total cost of the policy (see Guyader, Daures 2000). Of course, the regulator may use a tendering system to select the best offers though it would also lead to some adverse effects when collusion occurs between fishermen (Nautilus 1997). Transferable rights based system such as individual transferable quotas or transferable licence are often considered as a substitute for decommissioning schemes to reduce fishing capacity. Market signals provide incentives for economic agents to rationalise fisheries exploitation by rights consolidation. However, capacity is not scrapped by this process when the capital is non malleable or when the opportunity cost of capital is positive. This leads in most cases to a transfer of redundant capacity to other fisheries inside or outside the country but always in the fishing industry. Capacity remains on a short or medium term basis in the fishery sector if not on a fishery subject to individual transferable quotas. Even if decommissioning schemes do not reduce the incentives of capital and labor stuffing, they may be seen as a necessary tool to reduce capacity and to adjust the fleet to the desired levels. The principle of cost recovery could be used to share the cost of the programs that 
benefit to the fishers and that may provide incentives for the implementation of better means of controlling the increase in capacity through the implementation of right based fishing.

in order to assess the reduction in fishing mortality on the dynamics of the resource On the basis of certain assumptions relative to functions of production, and days spent at sea as an exogenous variable, the model is able to calculate crew and skipper incomes and boat-owner revenues for each year, not only for scallop campaigns (October to April) but also for the other activities carried out during the whole year. We assume that capacity reduction does not lead to any effect on the other stocks.

. is expressed by the harvesting function

Though the biological impact of decommissioning schemes can only be valued regarding scallop stocks, the economic impact can be assessed especially in terms of scallop activity, but also considering the different activities as a whole. 


\section{References}

Anderson, L. G., 1980 Necessary Components of Economic Surplus in Fisheries Economics. Canadian Journal of Fisheries and Aquatic Sciences, 37:858-870.

Anderson, L. G. 1998. A closer look at buyback programmes: a simulation approach. in Eide and Vassdal (Ed.) Proceedings of the IIFET conference, The Norwegian College of Fishery Science, University of Tromso (1) $110-119$

Anonym. 1990. Report of an independent group of experts on the guidelines for the preparation of the multi annual guidance programmes in relation to the fishing fleets for the period 1992-1996, Internal document, European Commission, Brussels, 19.11.90 (The "Gulland” Report)

Anonym. 1996. Report of an independent group of experts to advise the European Commission on the fourth generation of multi-annual guidance programmes 26.4.96 XIV/298/96-EN (The “Lassen” Report)

Anonym. 1997. Multi-Annual Guidance Programmes: Review of National Experiences, Working Document $n^{\circ} 8$ of the Concerted Action (AIR CT94 1489), April. + Annexes.

Boncoeur, J., Le Gallic B. 1999. Enquêtes économiques sur les flottilles de la Manche, Rapport CEDEM, Brest.

Chuang, C. T., and X. Zhang. 1998. Review of Boat Buyback Schemes and Experience in Chinese Taipei, Paper presented at the Workshop on Impact of Government Financial Transfers on Fisheries Management, Resource Sustainability, and International Trade. Manila, Philippines, 17-19 Aug.

Chuang, C.T. 1999. On the Fishing Boat Buyback Programme: The Taiwan Experience, mimeo 14 p.

Food and Agricultural Organization of the United Nations (1997). FAO Technical Guidelines for Responsible Fisheries No. 4: Fisheries Management, Rome.

Fifas, S., Dao J.C., and J. Boucher. 1990. Un modèle empirique du recrutement. Exemple de la coquille SaintJacques (Pecten maximus, L.) en baie de Saint-Brieuc (Manche, France). Aquatic Living Resources, 3:1328.

Fifas, S. 1993. Un modèle de capturabilité pour le stock de coquilles Saint-Jacques (Pecten maximus, L.) en baie de Saint-Brieuc (Manche, France), in Les recherches françaises et évaluation quantitative et modélisation 
des ressources et des systèmes halieutiques. Halieumétrie, Rennes 29/06-1/07/93, Actes du colloque. 141155.

Frost, H., Lanters, R., Smit, J., and P. Sparre. 1995. An appraisal of the effects of the Decommissioning Schemes in the case of Denmark and the Netherlands. DIFER, South Jutland University Press, Esbjerg, Denmark, $251 \mathrm{p}$.

Giguelay, T. 1999.French decommissioning schemes : appraising their place in public assistance to the fishing industry and their impact on fishing capacity. A preliminary analysis, presented at the Xith annual conference of the EAFE, Dublin, 7-10 April, 13p.

Greboval, D. and G. Munro. 1997. Overcapitalization in World Fisheries: Underlying Economics and Methods of Control. Food and Agriculture Organization of the United Nations, Rome.

Gréboval, D., and G. Munro 1998. Overcapitalisation and excess capacity in World Fisheries : underlying economics and methods of control. FAO Technical Working Group on the management of Fishing Capacity, La Jolla, USA, 15-18 April.

Guyader, O. 1998a. Evaluation économique et simulation des effets des régulations sur les comportements des agents : le cas des pêcheries de thon germon de l'Atlantique Nord-Est. Thèse de doctorat es sciences économiques, Université de Rennes 1, juin 1998, 421 p.

Guyader, O. 1998b. Transition from Open Access to Regulatory system with Subsidies: the case of the French Driftnet Fleet. Proceedings of the first Concerted Action Workshop on Economics and the Common Fishery Policy, UK, 28-30 October, CEMARE Miscellaneous Publication nº44 1999, 109-124.

Guyader, O., and S. Fifas. 1999. Modélisation bioéconomique de la pêcherie de coquilles Saint-Jacques de la baie de Saint-Brieuc, Rapport interne IFREMER, 113p.

Guyader O., and F. Daurès. 2000. Economic analysis of the impact of buyback programs and the role of financial incentives schemes: application to a limited entry French fishery. In Lindebo and Vestergaard (eds.) Proceedings of the XIIth Annual Conference of the European Association of Fisheries Economist, 65-90. 
Hatcher, A., and K. Robinson (eds.) 1998. Overcapacity, Overcapitalisation and subsidies in European fisheries, Proceedings of the first Concerted Action Workshop on Economics and the Common Fishery Policy, UK, 28-30 October, CEMARE Miscellaneous Publication n44 1999, vi+282p.

Hatcher, A. 2000. Subsidies for the European fishing fleets: the European Structural Policy for fisheries 19711999”, Marine Policy 24:129-140.

Holland, D., Gudmundsson, E., and J. Gates. 1999. Do fishing boat buyback programmes work: a survey of evidence, Marine Policy 23:47-69.

Holland, D. 1999. On direct and indirect management of fishing capacity, Marine Resource Economics 14:263267.

Ikiara, M. M., and J. G. Odink. 2000, Fishermen Resistance to exit fisheries" Marine Resource Economics 14: $199-213$

Metzner, R., and P. Rawlinson. 1998. Fisheries structural adjustment: Towards a national framework, Prepared for management committee standing Committee for fisheries and aquaculture Australia. Fisheries Victoria Department of Natural Resources and Environment, Department of Primary industries and Energy, Canberra. 253 p.

Nautilus. 1997. The economic evaluation of the fishing boats (decommissioning) schemes, Nautilus Consultants, Edinburgh, September, 106 p.

Newton, C., 1998.Review of issues for the control and reduction of fishing capacity on the high seas FAO Technical Working Group on the management of Fishing Capacity, La Jolla, USA, 15-18 April.

OECD. 1997. Towards sustainable fisheries: economic aspects of the management of living marine resources Paris, OECD publications.

Ricker, W.E. 1954. Stock and recruitment. J. Fish. Res. Board Can. 11:559-623.

Townsend, R.E. 1985. On capital Stuffing in regulated fisheries. Land Economics 61:195-197.

Wenninger, Q. R., and R. E. Just. 1997. An analysis of the transition from Limited entry to transferable quota: non marshalian principles for fisheries management. Natural Resource Modelling 10:53-83 


\section{ANNEX}

\section{Individual growth}

The individual growth model of scallop in the Saint-Brieuc Bay is expressed by a Von Bertalanffy modified equation (Guyader and Fifas 1999) :

$L(t)=\left(L \infty-\frac{a \cdot C^{b}}{K}\right) \cdot[1-\exp (-K \cdot(t-t 0))]$

where :

$\mathrm{L} \infty=$ theoretical maximum asymptotical size $; \mathrm{K}=$ parameter associated to growh rate; $\mathrm{t}_{\mathrm{o}}=$ theoretical age corresponding to $\mathrm{L}(\mathrm{t})=0 ; \mathrm{C}=$ surface rate covered by Crepidula fornicata (species competitor of scallops); a and $\mathrm{b}=$ parameters of the model. The surface rate covered by competitor species sis expressed by a logistical equation not specified here. In the example of the referenced scallop stock, the growth curve is linked with following values of parameters : $\mathrm{L} \infty=113.2681 \mathrm{~mm} ; \mathrm{K}=0.5842$ years $^{-1} ;$ to $=0.2380$ years ; $\mathrm{a}=7.5$ mm.years ${ }^{-1}$ and $\mathrm{b}=3$ (no dimension).

\section{Natural mortality and recruitment}

In the case of exploited stocks, it is difficult to give with certainty an instantaneous coefficient of mortality. Analogy reasoning by studying the same species, located in an area not far from those considered and non- 
exploited (e.g. west Ireland). A coefficient equal to 0.2 is used in the spreadsheet. An annual average recruitment is considered throughout the simulation even if a stochastic approach based on stock/Recruitment relationship of Ricker (1954) is available.

\section{Dredge selectivity}

The dredge selectivity $\operatorname{sel}_{i}$ versus scallop size $L_{i}$ is represented by a logistical equation (Fifas 1991):

sel $_{i}=\frac{1}{1+\exp \left(-\alpha \cdot\left(L_{i}-L 50\right)\right)}$

with :

$\alpha=$ parameter linked to deviation of selection $\left(\alpha=2 \cdot \ln (3) /\left(\mathrm{L}_{75}-\mathrm{L}_{25}\right) ;\right.$ see paragraph above $) ; \mathrm{L}_{50}=$ scallop size corresponding to $50 \%$ of retention by dredge meshes. In dredge selectivity functions, it can be written that : $\mathrm{L}_{75^{-}}$ $\mathrm{L}_{25}=\Psi(\mathrm{Lm})$ et $\mathrm{L}_{50}=\Phi(\mathrm{Lm})$ (where : $\mathrm{Lm}=$ mesh size $; \Psi$ and $\Phi=$ functions). The following relationships are valid :

$\mathrm{L}_{75}-\mathrm{L}_{25}=0.2853 . \mathrm{Lm}-18.5350$ (linear approximation is limited for mesh sizes $\mathrm{Lm} \geq 65 \mathrm{~mm}$ ) and $\mathrm{L}_{50}=0.8191 . \mathrm{Lm}$ +12.4570 .

\section{Technical progress}

This spreadsheets try to integrate these effects by introducing a new parameter measuring autonomous technical progress in the function of production $(\Delta \mathrm{a})$. Considering technical progress $(\Delta \mathrm{a})$ each year $(t)$ gives the equation : 
$q_{v j}\left(N_{j}, t\right)=\left[1+\Delta a \cdot\left(t-t_{0}\right)\right] \cdot \exp \left[\frac{N_{j} k W_{v} \cdot\left[1+\Delta a \cdot\left(t-t_{0}\right)\right]}{\alpha+\beta \cdot N_{j} k W_{v} \cdot\left[1+\Delta a \cdot\left(t-t_{0}\right)\right]}\right]$

$\left(t_{0}\right)$ designing initial year, 1984 for this model 
${ }^{1}$ The MAGP funding by the European Union is part of the structural policy budget which is also dedicated to the building and modernisation of the fleets (Giguelay 1999) (Hatcher 2000)

${ }^{2}$ In France, the scallop landings are prohibited from May to October in order to prevent to sanitary considerations.

${ }^{3}$ These decommissioning programs consist in financial subsidies delivered to a vessel owner who is fishing in the European waters and applies to exit his vessel from the fishery activity. The design of decommissioning programs in each member state has to obey to some European recommendations if the UE contribution is required for the financing of the exit. Three major regulations must be noticed : the council regulations 4028/86, 3944/90 and 2080/93 which have successively fixed : a maximum subsidies amount per size category of vessel (Gross Registered Tonnage categories), some restrictive criteria such as the age of vessel, the EU contribution to the funding of the exit if these criteria are respected. The French fleet is distributed among six GRT categories to fix premium rate and for each kind of exit/ GRT category, the premium is composed with a variable part and a fix part. In addition to the PME system, buyback programs have been regularly implemented to achieve the MAGP objectives when some delays appeared. Over the period 1991-96, four buyback programs have been implemented. The first plan (the so called Mellick plan implemented in 1991) was predominant and has concentrated around $70 \%$ of the total public expenses to reduce the fleet capacity over 1991-96. Meanwhile, the amounts allocated by the EU and French Government to decommissioning schemes represented only slightly more than $1 \%$ of the total expenditures of these authorities in aid to the fishery sector over the same period (Giguelay 1999).

${ }^{4}$ Vessel size limit has been bounded at 13 meters and engine power must not go beyond $185 \mathrm{~kW}$ since 1990 , except for vessels using a licence before this date and benefiting for historical rights.

${ }^{5}$ Fishing permits as Permis de Mise en Exploitation.

${ }^{6}$ According to this assumption, it is not possible to calculate consumer surplus effects due to price variation

${ }^{7}$ In a situation of perfect capital markets, the individual psychological discount rate and the capital cost rate are equal.

${ }^{8}$ It is also possible to consider insurance value as a proxy of capital value though this value changes during the simulation according to the ship's obsolescence and wear. 